OPEN ACCESS

Edited by:

Chunfu Zheng,

University of Calgary, Canada

Reviewed by: Jian Ma,

Harbin Medical University, China Chengmin Wang, Guangdong Institute of Applied Biological Resources, China

*Correspondence: Yanbing $\mathrm{Li}$

liyanbing@caas.cn

Hongliang Chai Hongliang_Chai@hotmail.com Xiangwei Zeng

xiangwei_zeng@163.com

tThese authors have contributed equally to this work

Specialty section:

This article was submitted to

Virology,

a section of the journal

Frontiers in Microbiology

Received: 24 December 2021 Accepted: 11 February 2022

Published: 01 March 2022

Citation:

Zhai B, Liu L, LiX, LvX, Wu J, Li J,

Lin S, Yin Y, Lan J, Du J, Wu C, Wen $Y$, Wang $Y$, Wang Y, Hou Z, Li Y,

Chai $H$ and Zeng $X$ (2022) The

Variation of Duck RIG-I-Mediated Innate Immune Response Induced by

Different Virulence Avian Influenza

Viruses

Front. Microbiol. 13:842721

doi: 10.3389/fmicb.2022.842721

\section{The Variation of Duck RIG-I-Mediated Innate Immune Response Induced by Different Virulence Avian Influenza Viruses}

\author{
Boyu Zhai ${ }^{1 \dagger}$, Lanlan $\mathrm{Liu}^{2 \dagger}$, Xiang $\mathrm{Li}^{1+}$, Xinru $L v^{1}$, Jinyan $\mathrm{Wu}^{1}$, Jing $\mathrm{Li}^{1}$, Shengze $\mathrm{Lin}^{1}$, \\ Yuxiang Yin', Jiaqi Lan', Jianan Du', Chenwei Wu' ${ }^{1}$, Yi Wen', Yajun Wang ${ }^{1}$, Yulong Wang', \\ Zhijun Hou ${ }^{1}$, Yanbing Li ${ }^{3 *}$, Hongliang Chai ${ }^{1 *}$ and Xiangwei Zeng ${ }^{1 *}$
}

\begin{abstract}
'State Forestry Administration Key Laboratory of Wildlife Conservation, College of Wildlife and Protected Area, Northeast Forestry University, Harbin, China, ${ }^{2}$ College of Basic Medical Science, Heilongjiang University of Chinese Medicine, Harbin, China, ${ }^{3}$ Chinese Academy of Agricultural Sciences Harbin Veterinary Research Institute, Harbin, China
\end{abstract}

In recent years, the emerging highly pathogenic avian influenza (HPAl) $\mathrm{A}(\mathrm{H} 5 \mathrm{~N} 8)$ virus has been reported with features of widely spread, an expanding host range, and cross-species transmission, attracting wide attention. The domestic duck plays a major role in the epidemiological cycle of the HPAI H5N8 virus, but little is known concerning innate immune responses during influenza infection in duck species. In this study, we used two wild-birdorigin viruses, $\mathrm{H} 5 \mathrm{~N} 8$ and $\mathrm{H} 4 \mathrm{~N} 6$, to conduct duck infection experiments, and detect the load of the two viruses, and retinoic acid-inducible gene I (RIG-I) and interferon $\beta$ (IFN- $\beta$ ) in the host's natural immune response. Through comparison, it is found that the expression levels of RIG-I and IFN- $\beta$ are both fluctuating. The innate immunity starts rapidly within $6 \mathrm{~h}$ after infection and is inhibited by the virus to varying degrees. The expression of RIG-I and IFN- $\beta$ decreased on $1-2$ days post-infection (dpi). The HPAI H5N8 virus has a stronger inhibitory effect on RIG-I than the low pathogenic avian influenza (LPAI) H4N6 virus and is the strongest in the lungs. After infection with HPAI H5N8 virus, 2 dpi, viral RNA replicates in large amounts in the lungs. It has been proven that RIG-I and IFN- $\beta$ play an important role in the innate immune response of ducks to HPAI H5N8 virus infection, especially in the lungs. The main battlefield of RIG-I and IFN- $\beta$ after infection with the LPAI H4N6 virus is in the rectum. Both viruses have been effectively controlled after $7 \mathrm{dpi}$. These results will help to understand the transmission mechanisms of avian influenza virus in wild ducks and help effectively prevent and control avian influenza.

\section{Keywords: AIV, H5N8, H4N6, duck, RIG-I, IFN- $\beta$, lung, rectum}

\section{INTRODUCTION}

Avian influenza, a highly contagious respiratory viral disease caused by the avian influenza virus (AIV), continues to impair the birds and human public health with enormous economic losses alarmingly worldwide. According to the antigenic difference between surface hemagglutinin (HA) and neuraminidase (NA), AIV is divided into 18 different HA subtypes and 11 different 
NA subtypes (Tong et al., 2013). According to the pathogenicity of AIV to chickens, it is divided into highly pathogenic avian influenza virus (HPAIV) and low pathogenic avian influenza virus (LPAIV).

Wild birds, especially waterfowl, are considered the natural hosts of AIV and the source of influenza viruses in other hosts (Webster et al., 1992). Except for H17N10 and H18N11, which are currently only isolated from bats (Zhu et al., 2013; Wu et al., 2014), almost all subtypes of AIV can be isolated from wild waterfowl (Piaggio et al., 2012; Zhang et al., 2012). Therefore, wild birds play an important role in the continued existence and spread of AIV. The role of wild birds in spreading LPAIV is recognized, and the situation of wild birds spreading HPAIV is more complicated. Studies have found that some wild birds (such as whooper swans, cormorants, bar-headed geese, and grebes; Spackman et al., 2009; Okamatsu et al., 2010; Albini et al., 2014; Muzyka et al., 2019) will die on a large scale and quickly after being infected with HPAIV, so they have little effect on the long-distance transmission of the virus. Wild ducks (such as mallards) are less likely to die after being infected with HPAIV and seem to have obvious resistance to HPAIV, which many studies have also confirmed (SturmRamirez et al., 2005; Lee et al., 2016; Pantin-Jackwood et al., 2016). Therefore, wild ducks can migrate long distances in an asymptomatic state, and within a certain time frame, the virus can be excreted with their feces to cause influenza transmission.

Avian influenza viruses show obvious differences in virulence to different species of wild birds. Wild ducks show obvious tolerance. What is the molecular mechanism behind it? Immunity is an important barrier for keeping animals healthy, and especially, the natural immune response is the first line of defense against pathogenic infections. RIG-I is considered the most important pattern recognition receptor that initiates the body's innate immune response during influenza virus infection. Due to the complex living environment of wild ducks, the infection background is unclear. The basic level of natural infection of different individuals varies. Therefore, this study selected domestic ducks artificially bred from mallard ducks as the model animal. The wild-bird-origin HPAIV caused the global H5N8 avian influenza epidemic in 2020-2021 (A/Whooper swan/Henan/h4/2016_H5N8), common wild bird LPAIV (H4N6) is used as the research object. Explore the differences in the innate immune changes caused by HPAIV and LPAIV in duck respiratory tract, intestines, and immune organs, through the infection experiment on SPF ducks, from the direction of RIG-1 mediated innate immunity. Try to analyze the possible molecular mechanism of duck innate immunity in influenza virus infection tolerance.

\section{MATERIALS AND METHODS}

\section{Virulent Strains}

Two viruses were used for the animal study. An H5N8 virus, termed A/Whooper swan/Henan/h4/2016 (Hn/h4), was isolated from a dead whooper swan in November 2016 Henan Province, China. Another H4N6 virus, termed A/Shorebird/Liaoning/ d59/2018 ( $\mathrm{Ln} / \mathrm{d} 59$ ), was isolated during our active surveillance of AIVs in April 2018, in Liaoning Province, China. Viruses were isolated with 9-10-day-old specific-pathogen-free (SPF) embryonated chicken eggs at National Avian Influenza Reference Laboratory of Harbin Veterinary Research Institute. Allantoic fluid was harvested after $72 \mathrm{~h}$ incubation, and the hemagglutinin (HA) activity was assayed. A hemagglutinin inhibition (HI) assay was performed preliminarily to determine the HA subtype of the isolated virus. Viral RNA was extracted from HA positive samples from the incubated allantoic fluid using a QIAamp Viral RNA Mini Kit (QIAGEN, Germany), reverse transcribed using the primer Uni12. The PCR products of eight fragments of the isolates were sequenced using Sanger Sequencing. The sequence data were compiled using the SeqMan program (DNASTAR, Madison, WI, United States). Hn/h4 possessed multiple basic amino acids (-RERRRKR $\downarrow$ GLF-) at the HA cleavage site, characteristic for HPAIV. Ln/d59 was classified as LPAI due to the -PEKASR $\downarrow$ GLF-amino acid motif.

\section{Animals}

SPF Shaoxing Ducks were used as experimental animals. All ducks were hatched and raised until they reached within $720-800 \mathrm{~g}$ body weight at 4 weeks of age at the Negative pressure isolator in Laboratory Animal Center of Harbin Veterinary Research Institute.

\section{Animals Infection Experiment}

The 50\% egg infective doses (EID50) of the harvested allantoic fluids of $\mathrm{Hn} / \mathrm{h} 4$ and $\mathrm{Ln} / \mathrm{d} 59$ were determined by the method of Reed and Muench. Ninety SPF ducks were divided into three equal groups containing 30 ducks each. These groups were intranasally and orally inoculated with $0.2 \mathrm{ml} 10^{6}$ EID50 of Hn/h4 (HPAIV group), Ln/d59 (LPAIV group), and Phosphatebuffered saline (PBS; control group), respectively. Three ducks of each group were randomly selected and humanely euthanized at the $1 / 12,1 / 4,1,2,3,5,7$, and $10 \mathrm{dpi}$. Rectum, lung, and spleen were collected aseptically, dead ducks were selected priority, and all samples were frozen and stored at $-80^{\circ} \mathrm{C}$ until total RNA extraction.

\section{Quantitative Real-Time PCR}

Total RNA was extracted using Column Animal RNAout kit (Tiandz). The total RNA was reverse transcribed into cDNA with the primer oligo-dT for RIG-I and IFN- $\beta$ expression determination by the relative quantitative method. The specific quantitative primers were designed using Oligo7 software, as followed, RIG-I (forward: qRIG-IF: 5'-GATACTCTCTCCCAAAACAGCAAGAAAGAT-3' and reverse: qRIG-IR: $5^{\prime}$-GAAAAGGGCTCTACATATCCTGC - $3^{\prime}$ ), IFN- $\beta$ (qIFN- $\beta$ F: 5 '-CCCCGCAACCTTCACCT-3' and qIFN- $\beta$ R: $5^{\prime}$-CCGAAGTGGCTGGGAGATGC- $3^{\prime}$ ), and $\beta$-actin (q $\beta$-actinF: $5^{\prime}$-GCAAGTACTCTGTCTGGATTGGAG- $3^{\prime}$ and q $\beta$-actinR: 5'-TTTGCGGTGGACAATGGA- $3^{\prime}$ ). Quantitative real-time PCR (qPCR) was performed on an ABI-7500 using TB Green ${ }^{\mathrm{TM}}$ Premix Ex Taq ${ }^{\mathrm{TM}}$ (Tli RNaseH Plus; Takara). The qPCR mixture consisted of $1 \mu \mathrm{l}$ of cDNA sample, $3 \mu \mathrm{l}$ nuclease-free water, $5 \mu \mathrm{l}$ of $2 \times \mathrm{TB}$ Green Premix Ex Taq II(Takara), $0.4 \mu$ l of each gene-specific primer 
( $10 \mathrm{mM}$ ), and $0.2 \mu \mathrm{l}$ of ROX II(Takara). The qPCR cycling conditions were as: 1 cycle of $95^{\circ} \mathrm{C}$ for $30 \mathrm{~s}$, followed by 40 cycles of $95^{\circ} \mathrm{C}$ for $5 \mathrm{~s}, 60^{\circ} \mathrm{C}$ for $34 \mathrm{~s}$.

The total RNA was reverse transcribed into cDNA with the primer Uni12 for viral loads determination by the absolute quantitative method. The specific quantitative primers were designed using Oligo7 software, as followed, H5N8 AIV (qH5N8F: 5'-GACTGGTTCATGCTCATGCC-3' and qH5N8R: $5^{\prime}$-ACGGTGAGATTTCTCCCACAA- $3^{\prime}$ ) and H4N6 AIV (qH4N6F: 5'-CTCTCGTTATTGCCGCAAGC-3' and qH4N6R: $5^{\prime}$-TCAGGCACTCCTTCCGTAGA-3'). To prepare standard curves, we cloned small fragments of the two viruses into $\mathrm{pMD}^{\circledR} 18$-T vector (Takara), respectively, and verified by Sanger sequencing. PCR efficiency (E) was tested via the use of standard curves, using the formula $\mathrm{E} \%=10^{(-1 / \text { slope })} \times 100$, with $90-110 \%$ efficiency considered adequate for the purposes of this study. The qPCR procedure is the same as the relative quantification method described above.

\section{Statistical Analysis}

The threshold cycle $(\mathrm{Ct})$ value was normalized to the housekeeping gene $\beta$-actin; the expression levels of each gene were normalized to the expression level of the endogenous control ( $\beta$-actin) and were expressed as fold changes relative to the control group using the $2^{-\Delta \Delta \mathrm{Ct}}$ method (Livak and Schmittgen, 2001). Relative gene expression (i.e., fold change) was then calculated as the geometric mean of expression in each group (i.e., time point), with the experimental time points $(1 / 12,1 / 4$, $1,2,3,5,7$, and $10 \mathrm{dpi}$ ) scaled in comparison with the control group (1/12 dpi). Expression in the control group was set to 1 and relative fold change in target genes was expressed as positive values for upregulated genes and negative values for downregulated genes. Statistical comparison of changes in gene expression use t-text analysis. Viral loads were detected by qPCR with absolute quantification. Their respective copy numbers were calculated based upon the molecular weight of the plasmid for standards. Copy numbers for each viruses were then calculated based upon $\mathrm{Ct}$ values compared to standard curve. Statistical analyses and data plotting were performed with GraphPad Prism v. 8.0.1 (GraphPad Software Inc.).

\section{RESULTS}

During the animal experiment, two ducks died in the HPAIV group, one on the 2nd day and the other on the 5th day, and there was no death in the LPAIV group and the control group. There were no obvious clinical symptoms in all groups. Through planning inspection, it was found that ducks in the HPAIV group had light yellow mucus in the trachea, flushing of the lungs, and swelling of the spleen to varying degrees as the number of days increased. Only the spleen was swollen in the LPAIV group. The control group was healthy and free of symptoms.

According to the analysis of $\mathrm{qPCR}$ results, the relative expression change curves of RIG-I and IFN- $\beta$ and the copy number of the virus were drawn. In duck lungs (Figures 1A,B),
Hn/h4 will cause a short rise of RIG-I before $1 / 4 \mathrm{dpi}$, and then, the expression of RIG-I will drop below normal within $2 \mathrm{dpi}$, then start to rise and reach a peak at $3 \mathrm{dpi}$, ultimately, return to normal level in $10 \mathrm{dpi}$. The expression of IFN- $\beta$ is the same as the changing trend of RIG-I. Compared with the LPAIV group, the changing trend of RIG-I and IFN- $\beta$ expressions was delayed, and the peak appeared later. Ln/d59 only slightly increased at 1 and $5 \mathrm{dpi}$ after infection (Figure 2B). After the challenge, $\mathrm{Hn} / \mathrm{h} 4$ started to replicate in large quantities $1 \mathrm{dpi}$ (Figure 2A). The content of viral RNA in the lungs was at a high level within $2 \mathrm{dpi}$, which was extremely significantly different from the $1 / 12$ dpi. $(p<0.001)$. After 3 days, $\mathrm{Hn} / \mathrm{h} 4$ was inhibited and began to decline rapidly but $\mathrm{Ln} / \mathrm{d} 59$ was rise again in $5 \mathrm{dpi}$.

After challenge with Hn/h4, RIG-I expression in the rectum of ducks was similar to that in the lungs (Figures 1C,D). Unlike the lungs, the highest peak of RIG-I expression in the rectum appeared at $1 / 4 \mathrm{dpi}$ instead of $3 \mathrm{dpi}$. The expression of IFN- $\beta$ was highly upregulated before $1 / 4 \mathrm{dpi}$, decreased below the normal level at $1 / 4-1 \mathrm{dpi}$, and began to rise after $1 \mathrm{dpi}$. The changing trend of RIG-I and IFN- $\beta$ is high expression at $1 / 4 \mathrm{dpi}$, and the expression level rises briefly and rapidly. The changing trend of RIG-I and IFN- $\beta$ expressions caused by $\mathrm{Ln} / \mathrm{d} 59$ in the rectum is the same, and it is also in the rising stage before $1 / 4 \mathrm{dpi}$, but both are lower than $\mathrm{Hn} / \mathrm{h} 4$. Two peaks are formed at $1 / 4 \mathrm{dpi}$ and $2 \mathrm{dpi}$. The highest copy number of $\mathrm{Hn} / \mathrm{h} 4$ in the rectum appears at $2 \mathrm{dpi}$, which is not significantly different from $1 / 12$ dpi $(p<0.5$; Figure 2A). The copy number of Ln/d59 increased rapidly at $2 \mathrm{dpi}$ and then decreased slowly and the peak copy number was significantly different from 1/12 dpi $(p<0.01$; Figure 2B).

The changing trend of RIG-I expression in the spleen of ducks infected with $\mathrm{Hn} / \mathrm{h} 4$ is consistent with that of the lung and rectum (Figures 1E,F). The highest peak of IFN- $\beta$ expression appeared at $5 \mathrm{dpi}$ after the challenge. Compared with $\mathrm{Ln} / \mathrm{d} 59$, the peak expression of RIG-I and IFN- $\beta$ appeared earlier and lower. The highest peak of RIG-I and IFN- $\beta$ expression after infection with $\mathrm{Ln} / \mathrm{d} 59$ appeared at $7 \mathrm{dpi}$. The copy number of $\mathrm{Hn} / \mathrm{h} 4$ increases rapidly after $1 / 4 \mathrm{dpi}$ and peaks at $2 \mathrm{dpi}$ and is significantly different from $1 / 12$ dpi $(p<0.01$; Figure 2A). The copy number of Ln/d59 in the spleen was low, and there was no obvious change, only a slight increase at 3 dpi (Figure 2B).

The representative time points were selected, and the expression levels of various genes in duck lung, rectum, and spleen simultaneously were compared based on the data. The expression of RIG-I in duck lungs infected with $\mathrm{Hn} / \mathrm{h} 4$ was higher than that of rectum and spleen at $3 \mathrm{dpi}$, and low expression at $1 / 4$, 2 , and $5 \mathrm{dpi}$. In the intestine, the expression of RIG-I was highest at $1 / 4 \mathrm{dpi}$ (Figure $3 \mathrm{~A}$ ). The situation of IFN- $\beta$ is similar to that of RIG-I, only slightly different at 2 dpi (Figure 3B). The expression of RIG-I in ducks infected with Ln/d59 was highest in the rectum at $1 / 4,2,3 \mathrm{dpi}$, especially at $1 / 4,2 \mathrm{dpi}$, and the lung and spleen were significantly different, while at $5 \mathrm{dpi}$, it was the highest in the spleen (Figure 3C). The expression level of IFN- $\beta$ is opposite to that of RIG-I. The expression level of IFN- $\beta$ is the highest in the spleen at $1 / 4,2$, and $3 \mathrm{dpi}$ and the highest in the intestine at $5 \mathrm{dpi}$ (Figure 3D). After infection with $\mathrm{Ln} / \mathrm{d} 59$, both RIG-I and IFN- $\beta$ are low expression in the lungs. 
A

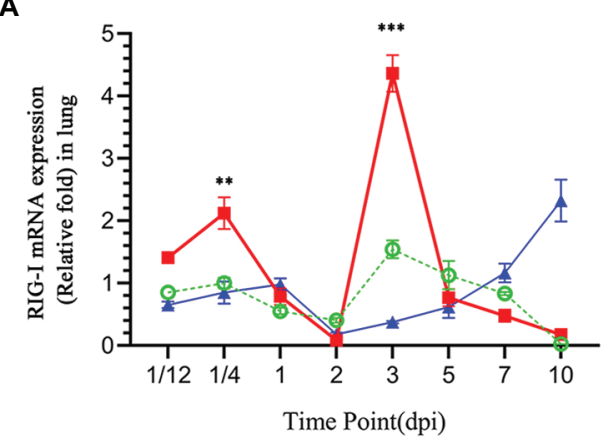

C

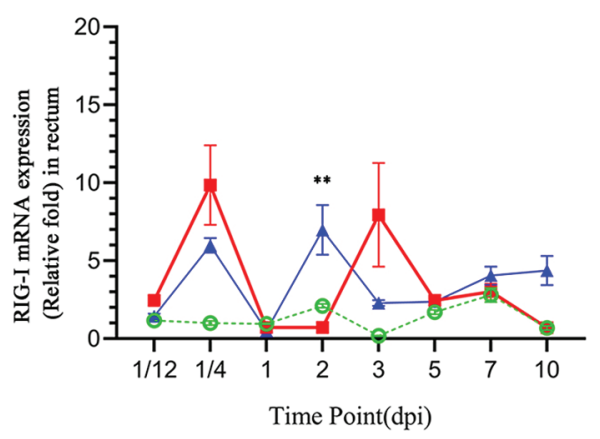

E

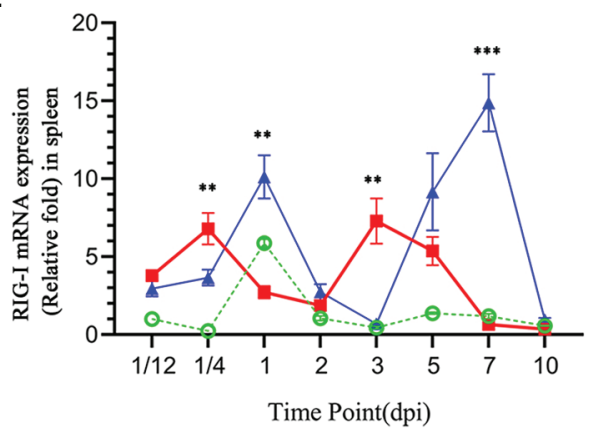

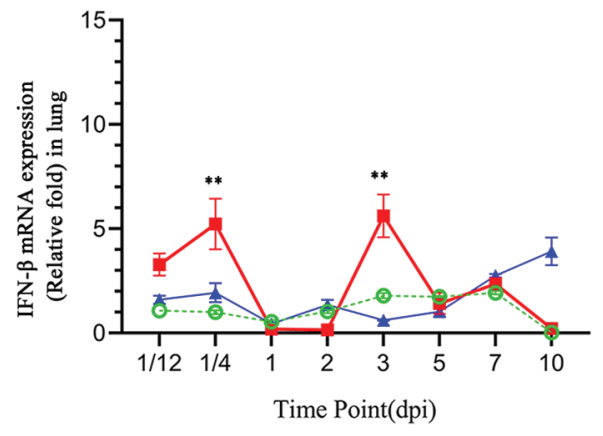

D

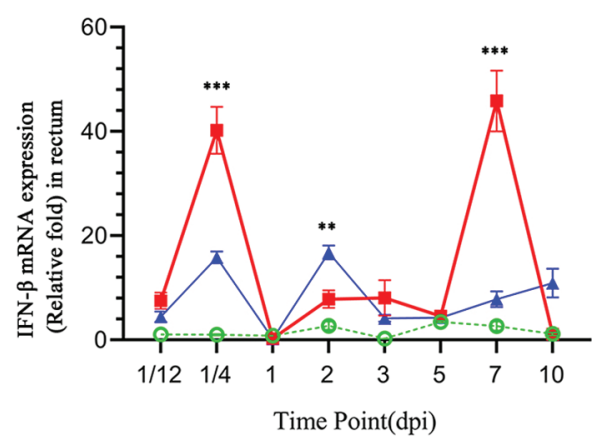

$\mathbf{F}$

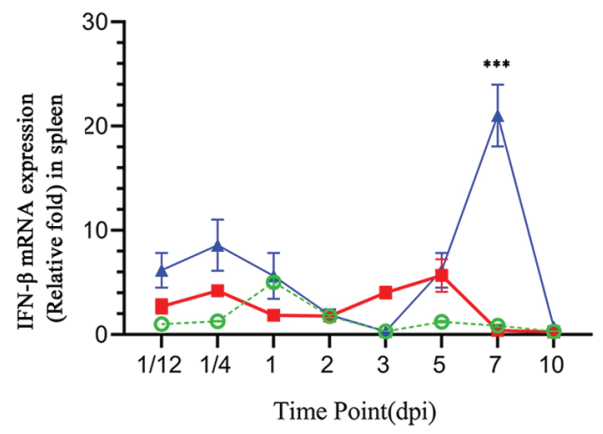

$\star$ Ln/d59 (LPAIV group)

FIGURE 1 | Changes in the expression levels of RIG-I and IFN- $\beta$ in different tissues. (A) Relative expression of RIG-I in the lung. (B) Relative expression of IFN- $\beta$ in the lung. (C) Relative expression of RIG-I in the rectum. (D) Relative expression of IFN- $\beta$ in the rectum. (E) Relative expression of RIG-I in the spleen. (F) Relative expression of IFN- $\beta$ in the spleen. Asterisks represent significant changes (t-test), ${ }^{* *}$ represents $p<0.01$, and ${ }^{\star \star \star}$ represents $p<0.001$.

\section{DISCUSSION}

\section{The Spread of HPAIV and LPAIV Among Wild Birds}

Studies have shown two main ways of transmission of AIV in wild birds. The virus infects the upper respiratory tract and then spreads to other hosts through droplets. The other is that the carrier excretes the virus into the water through excretion, and AIV uses water as a medium to spread to other hosts. AIV can maintain infectivity for more than 1 month in cold water and 4 days at room temperature (Webster et al., 1978).

The main replication site of HPAIV is in the upper respiratory tract of the host, and it is highly lethal to wild birds (Sturm-Ramirez et al., 2004). Most migratory birds cannot carry HPAIV for long-distance migration. The replication site of LPAIV is mainly in the intestine (Webster et al., 1978), which can be transmitted through the water as a medium, and most wild birds are not lethal after 


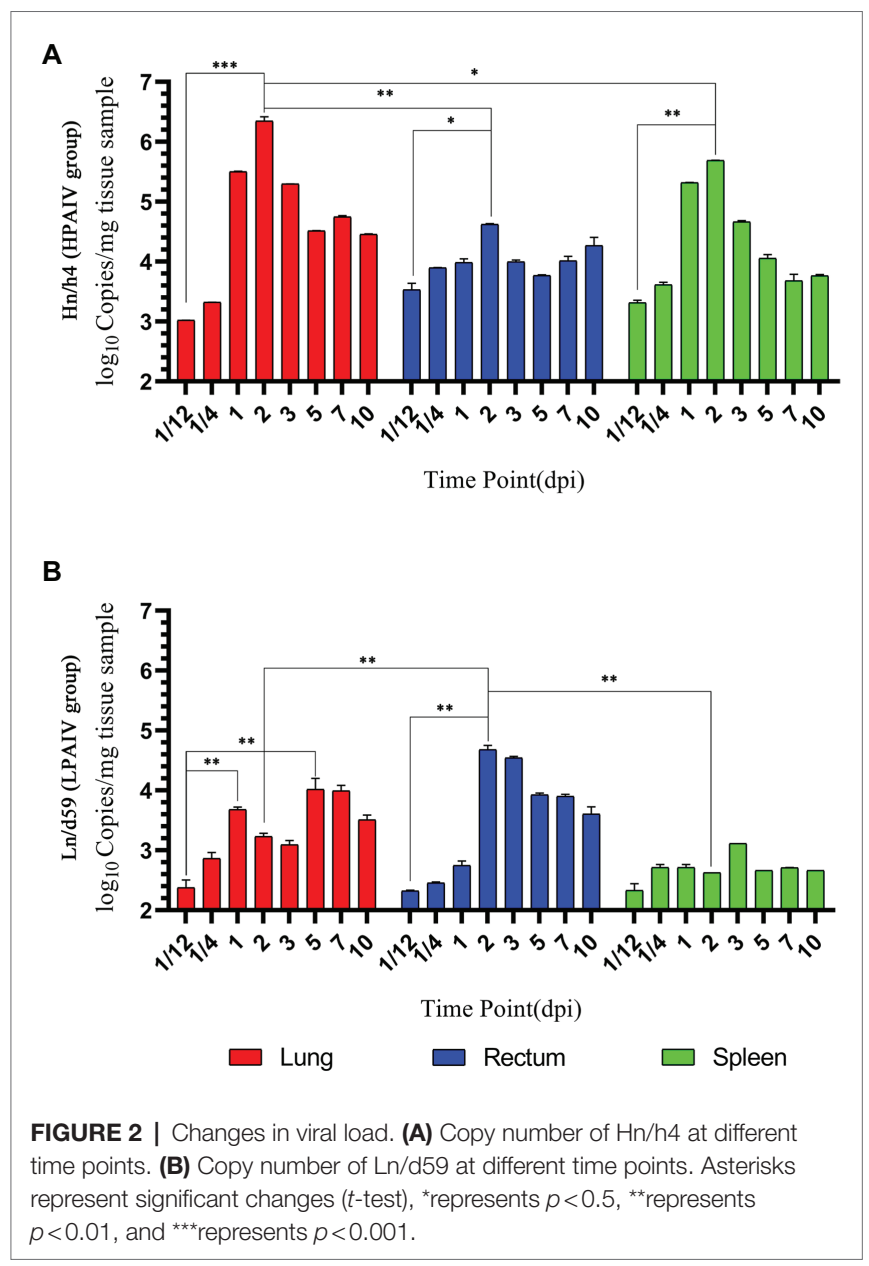

infection, and even no obvious symptoms will appear (Kida et al., 1980). For these reasons, LPAIV spreads across regions through the migration of wild birds. LPAIV is easy to mutate and recombine with other AIVs in the host body (Holmes et al., 2005; Rambaut et al., 2008; Marshall et al., 2013), which further enhances its virulence and transforms it into a more harmful HPAIV (Zhang et al., 2013).

At present, the AIV of the H5N8 subtype has gradually replaced the dominant position of $\mathrm{H} 5 \mathrm{~N} 1$ and has gradually become the dominant virus in the world, and cause a large number of wild birds to infect and die especially Anseriformes. A large amount of epidemiological and genetic evidence shows that wild ducks are not dying after being infected with the HPAI H5N8 virus and can carry the virus to spread over long distances (Global Consortium for H5N8 and Related Influenza Viruses, 2016; Nuñez and Ross, 2019). This situation was also confirmed in this experiment. The ducks did not die in large numbers after being infected with $\mathrm{Hn} / \mathrm{h} 4$, and there were no obvious symptoms. Therefore, wild ducks have important research value in transmitting the HPAI H5N8 virus. Because of the H4N6 subtype, AIV is the most common type of LPAIV, and it has a wider range of transmission. It is often isolated from wild waterfowl in many countries in Asia, Europe, Africa, and North America (Nguyen et al., 2005; Simulundu et al.,
2011). Therefore, Hn/h4 (H5N8) and $\mathrm{Ln} / \mathrm{d} 59$ (H4N6) were chosen to analyze the immune mechanisms between AIVs with different virulence, which will build the fundamental theoretical basis to prevent the cross-regional spread of HPAIV and LPAIV among wild birds.

\section{The Important Role of RIG-I in Resisting Avian Influenza Virus}

Innate immunity is the body's first barrier encountered by invading AIVs, and virus infection is detected by identifying pathogen-associated molecular patterns (PAMP) through pattern recognition receptors (PRR). These PAMPs are produced during pathogen infection (Janeway, 1989). Members of at least three different types of PRRs recognize influenza viruses through the innate immune system, namely, Toll-like receptors (TLRs), RIG-1-like receptors (RLRs), NOD-like receptors (NLRs), and C-type lectins Receptors (CLRs; Kawai and Akira, 2009). Among them, RLRs mainly include RIG-I, melanoma differentiationassociated gene 5 (MAD5), and Laboratory of genetics and physiology 2 (LGP2; Takeuchi and Akira, 2010).

Currently, RIG-I is recognized as one of the main pattern recognition receptors (PRR) for innate immunity against influenza viruses. RIG-I is activated by binding to viral RNA, causing conformational changes to activate downstream pathways. IKK $\alpha$ and IKK $\beta$ lead to the activation of nuclear factor- $\kappa \mathrm{B}(\mathrm{NF}-\kappa \mathrm{B}$; Servant et al., 2002; Hayden and Ghosh, 2011), and phosphorylation mediated by IKKe and TBK1 activates interferon regulatory factor 3/7 (IRF3/7; Sharma et al., 2003), which can cause the production of interferon, interferon-stimulating genes, and pro-inflammatory cytokines, and block the replication of the virus in the body (Goodbourn et al., 2000).

According to research, RIG-I does not exist in chickens (Barber et al., 2010). Although chickens without RIG-I can also produce interferon- $\alpha$ (IFN- $\alpha$ ) through other means, the expression of IFN- $\beta$ during influenza virus infection is largely dependent on RIG-I (Isaacs and Lindenmann, 1987). From the experimental data, the expression transformation trend of RIG-I and IFN- $\beta$ does have high similarity. The protective effect of IFN- $\beta$ during influenza infection cannot be replaced by IFN- $\alpha$ (Koerner et al., 2007; Barber et al., 2010). This results in that chickens are less resistant to AIV than ducks, and RIG-I plays a decisive role in it.

\section{Links Between Viral Load and Innate Immunity}

Studies have shown that AIV preferentially replicates in different tissues of the host, initially often depending on the type of linkage of cell surface glycoproteins. It is also specific in different tissues (Campbell and Magor, 2020). Usually HPAIV is more adaptable in the upper respiratory tract, and LPAIV is more adaptable in the intestine (Webster et al., 1978; Kida et al., 1980; Sturm-Ramirez et al., 2004; Vanderven et al., 2012). However, viral load cannot be explained by target cell limitation alone; there are also other factors such as innate immunity (Hagenaars et al., 2016). The distribution and expression changes of innate immune genes in tissues also have influence on them. 
A

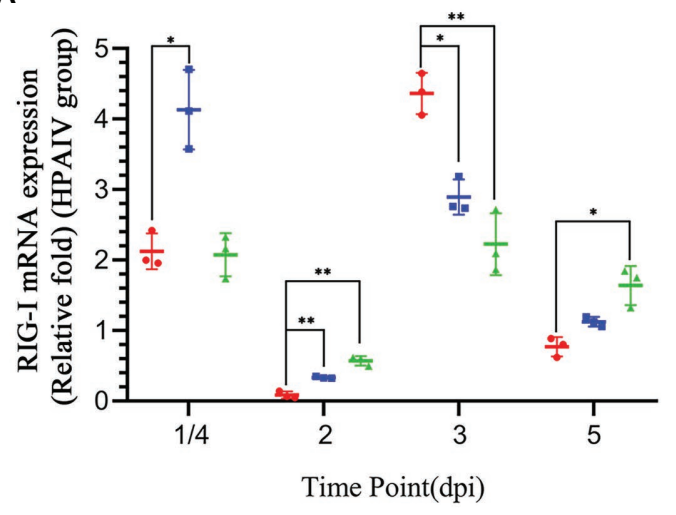

C

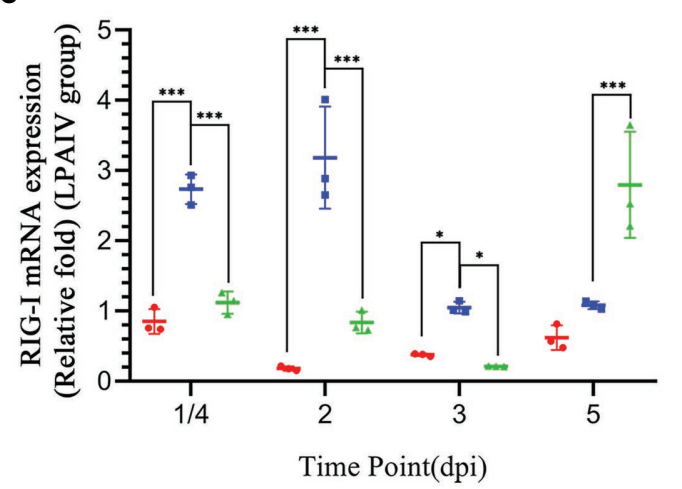

B

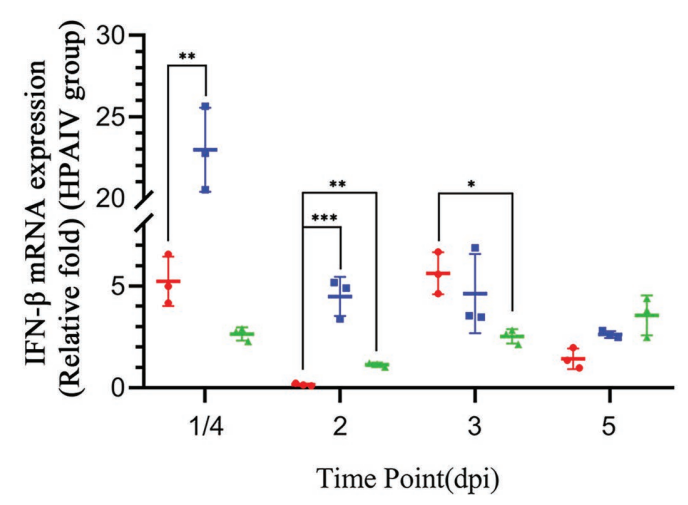

D

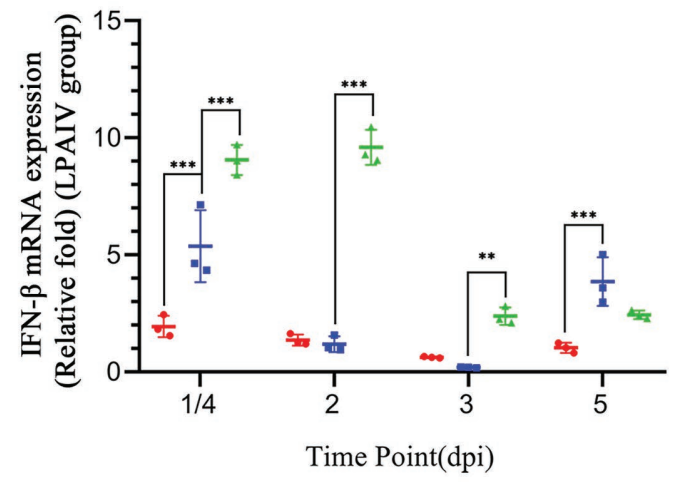

$\triangle$ spleen

FIGURE 3 | Comparison of the expression levels of RIG-I and IFN- $\beta$ in different tissues at specific time points. (A) The relative expression of RIG-I in different organs simultaneously after $\mathrm{Hn} / \mathrm{h} 4$ infection. (B) The relative expression of IFN- $\beta$ in different organs simultaneously after $\mathrm{Hn} / \mathrm{h} 4$ infection. (C) The relative expression of RIG-I in different organs simultaneously after Ln/d59 infection. (D) The relative expression of IFN- $\beta$ in different organs simultaneously after Ln/d59 infection. Asterisks represent significant changes ( $t$-test), ${ }^{\star}$ represents $p<0.5$, ${ }^{\star *}$ represents $p<0.01$, and ${ }^{* \star \star}$ represents $p<0.001$.

There are also differences in innate immunity elicited in tissues that replicate heavily after viral infection. This may be due to mutations in the amino acid sites of the virus, resulting in different virulence (Suttie et al., 2019). Generally, the innate immune response caused by HPAIV is more intense and that caused by LPAIV is milder (Fleming-Canepa et al., 2019). The link between viral load and innate immunity may be more complex than we currently understand. Further research is therefore required.

\section{Similar Innate Immune Response Caused by AIV of Different Virulence}

The data show that both viruses began to replicate in large numbers at 1-3 dpi and were effectively controlled after 7 dpi, which may be because the innate immune gene expression level is not high at 1-2 dpi, and the expression levels of RIG-I and IFN- $\beta$ are in a decline stage. After $7 \mathrm{dpi}$, adaptive immunity begins to take effect, and it usually takes about a week to produce antibodies (Kikkert, 2020). A large number of antibodies inhibited the replication of AIVs. At the same time, this also illustrates the important role of innate immunity against the avian influenza virus in the 7 days before infection.

The results showed a strong correlation between the expression changes of RIG-I and IFN- $\beta$ caused by the two AIVs with different pathogenicity. The expression of RIG-I and IFN- $\beta$ increased temporarily at $6 \mathrm{~h}$ after infection. According to research, $12 \mathrm{~h}$ after H5N6 avian influenza virus infection, the expression of RIG-I in ducks is also upregulated (Wu et al., 2019). The expression of RIG-I in the lungs of ducks infected with H9N2 AIV was also slightly upregulated (Cheng et al., 2015). These research results are consistent with the results of this experiment, but the time nodes of the experimental design are not intensive enough to accurately reflect how long the upward trend will continue. Innate immunity is the body's first barrier. Once a virus invades it, an immune response will occur quickly, preventing virus replication in a short period.

Interestingly, the expression of RIG-I and IFN- $\beta$ after infection with AVIs did not increase or decrease continuously but fluctuated. We speculate that this may be because downstream signals negatively regulate RIG-I to ensure that the innate immune response is strong enough but not too explosive. When the innate immunity 
is too strong, these responses are downregulated in time to protect the individual from damage (Robertson, 1998). It may also be due to the suppressive effect of the virus on innate immunity.

\section{Differences in Innate Immune Response Caused by AIVs of Different Virulence}

After a brief rise, the innate immunity genes may be suppressed. During the 1-2 dpi after challenge with $\mathrm{Hn} / \mathrm{h} 4$, RIG-I and IFN- $\beta$ expressions will continue to decline until they are lower than normal levels. It may be due to the interference of the virus's NS1 protein on the RIG-I pathway. NS1 protein can form a complex with RIG-I, causing RIG-I to be unable to be activated (Pichlmair et al., 2006; Guo et al., 2007; Mibayashi et al., 2007; Opitz et al., 2007). At the same time, it can also hinder the formation of IRF3/7 (Talon et al., 2000) and NF-кB (Wang et al., 2000), resulting in blocked signal pathways and unable to stimulate the formation of IFN. The NS1 protein can also inhibit the post-transcriptional processing and modification of host cell precursor mRNA from affecting IFN production (Kuo and Krug, 2009) so that the virus has a period of concealed replication after infection (Vanderven et al., 2012). The virus replicated in large numbers at this point and reached a peak in 2-3 dpi. The relationship between the virulence of the virus and the degree of influence of the NS1 protein on innate immunity is not clear. However, from the data results, $\mathrm{Hn} / \mathrm{h} 4$ has a stronger inhibitory ability on the innate immune gene RIG-I pathway than $\mathrm{Ln} / \mathrm{d} 59$.

Interestingly, the experimental data showed that the inhibitory ability of $\mathrm{Hn} / \mathrm{h} 4$ in the lung is stronger than that in the spleen and rectum. It may be because the main replication site of HPAIV is in the respiratory tract (Sturm-Ramirez et al., 2004; Vanderven et al., 2012), so it may show stronger inhibitory ability in the lung. Studies have shown that compared with the low pathogenic H5N1 AIV, the highly pathogenic H5N1 AIV inhibits the immune response in the respiratory tract by inhibiting the $\mathrm{C}-\mathrm{X}-\mathrm{C}$ chemokine receptor 4 (CXCR4) signaling pathway and promotes systemic infection in ducks (Massin et al., 2013). Some researchers have shown that after infection with low pathogenic H5N1 AIV, RIG-I expression increased significantly in the lungs on the first day (Barber et al., 2010). However, the expression of RIG-I in the lung after infection with the Hn/h4 HPAIV in this experiment showed a downward trend, and the expression was lower than that of the spleen and rectum at 2 days (Figure 3). This result shows that $\mathrm{Hn} / \mathrm{h} 4$ may also inhibit the CXCR4 signaling pathway and shows a stronger inhibitory effect on RIG-I in the lungs. In addition, the copy number of $\mathrm{Hn} / \mathrm{h} 4$ in the rectum at $1 / 4$ dpi is higher than that in the lung and spleen, and the upregulation of RIG-I and IFN- $\beta$ expression is caused by it is also the highest. The replication of $\mathrm{Hn} / \mathrm{h} 4$ is effectively controlled in the rectum, and there is no sudden sharp rise, showing that $\mathrm{Hn} / \mathrm{h} 4$ does not exert a strong inhibitory effect on innate immunity in the rectum as it does in the lung.

The results showed that as the copy number of $\mathrm{Ln} / \mathrm{d} 59$ increased in the rectum, the expression of RIG-I and IFN- $\beta$ also increased. They effectively resisted Ln/d59 and successfully prevented the virus from replicating. The copy number of Ln/ d59 in the lung and spleen is lower than that in rectum, especially in the spleen, which is basically at the detection limit. Although Ln/d59 caused little change in the expression of RIG-I and IFN- $\beta$ in the lung, it was different in the rectum and spleen. The expression of RIG-I in the intestine is significantly different from that in the lung and spleen at $1 / 4,2$, and 3 dpi. The expression of IFN- $\beta$ in the spleen was higher than that in the rectum and the lung at these time points, and there were significant differences (Figure 3D), which may be because the main replication site of $\mathrm{Ln} / \mathrm{d} 59$ is in the rectum, which has the same characteristics as other LPAIVs (Webster et al., 1978; Kida et al., 1980), and RIG-I in ducks is mainly distributed in the mucosal tissues in contact with air (Cheng et al., 2015). The spleen is an immune organ, and multiple immune pathways may cause the high expression of IFN- $\beta$ (John, 1994). Studies have shown that the spleen plays a particularly active role in the innate immune response to LPAI, which is consistent with the data from this experiment (Helin et al., 2018).

In summary, RIG-I and IFN- $\beta$ play an important role in the fight against $\mathrm{H} 5 \mathrm{~N} 8$ and H4N6 AIVs in ducks. Especially within a few hours after infection, the upregulation is rapid. Although the virus inhibits it within 1-2 days, it is eventually upregulated and hinders the increase in viral load. These two AIVs have different main replication sites, but $\mathrm{H} 5 \mathrm{~N} 8$ has a stronger ability to inhibit innate immunity than H4N6. Recently, there have been reports that many wild whooper swans and black-necked gray swans died after being infected with the $\mathrm{H} 5 \mathrm{~N} 8$ avian influenza virus (Muzyka et al., 2019; Li et al., 2021, 2022). We want to analyze further the causes of their deaths and the changes in RIG-I after infection with the $\mathrm{H} 5 \mathrm{~N} 8$ avian influenza virus. In the experiment, it can be seen that AIVs of different virulence will have significantly different effects on innate immunity. Will there be obvious differences in the resistance of different breeds of ducks to AIVs? We still need further research and discussion about whether there are other common rules in the interaction between AIVs and the body's immunity. In recent years, the pathogenicity of AIVs has been continuously enhanced, and the host range has become wider and wider, and at the same time, it continues to pose a threat to mammals, especially humans. However, the biggest problem is how to prevent AIVs from spreading across regions in wild birds. This study compared the differences in the innate immune mechanism after HPAIV and LPAIV infection and analyzed their transmission mechanisms. It is hoped that it can provide a theoretical basis for the large-scale spread of AIVs and help prevent, control, and treat AIVs in the future.

\section{DATA AVAILABILITY STATEMENT}

The original contributions presented in the study are included in the article/supplementary material, further inquiries can be directed to the corresponding authors. 


\section{ETHICS STATEMENT}

The animal study was reviewed and approved by Harbin Veterinary Research Institute, Chinese Academy of Agricultural Sciences, Heilongjiang, China.

\section{AUTHOR CONTRIBUTIONS}

BZ, LL, and XLi performed the phylogenetic analyses and the animal experiments and wrote the drafts of the manuscript. Xlv, JW, JLi, SL, YY, and JLa collected the surveillance samples and performed the Quantitative real-time PCR. JD, CW, and YWe

\section{REFERENCES}

Albini, K., Sigrist, G., and Keller, \& Hoop., (2014). Shedding of zoonotic pathogens and analysis of stomach contents in great cormorants (Phalacrocorax carbo sinensis) from Switzerland between 2007 and 2012. Schweiz. Arch. Tierheilkd. 156, 389-394. doi: 10.1024/0036-7281/a000611

Barber, M. R., Aldridge, J. R. Jr., Webster, R. G., and Magor, K. E. (2010). Association of RIG-I with innate immunity of ducks to influenza. Proc. Natl. Acad. Sci. U. S. A. 107, 5913-5918. doi: 10.1073/pnas.1001755107

Campbell, L. K., and Magor, K. E. (2020). Pattern recognition receptor signaling and innate responses to influenza A viruses in the mallard duck, compared to humans and chickens. Front. Cell. Infect. Microbiol. 10:209. doi: 10.3389/ fcimb.2020.00209

Cheng, Y., Huang, Q., Ji, W., Du, B., Fu, Q., An, H., et al. (2015). Muscovy duck retinoic acid-induced gene I (MdRIG-I) functions in innate immunity against H9N2 avian influenza viruses (AIV) infections. Vet. Immunol. Immunopathol. 163, 183-193. doi: 10.1016/j.vetimm.2014.12.009

Fleming-Canepa, X., Aldridge, J. R. Jr., Canniff, L., Kobewka, M., Jax, E., Webster, R. G., et al. (2019). Duck innate immune responses to high and low pathogenicity H5 avian influenza viruses. Vet. Microbiol. 228, 101-111. doi: 10.1016/j.vetmic.2018.11.018

Global Consortium for H5N8 and Related Influenza Viruses (2016). Role for migratory wild birds in the global spread of avian influenza H5N8. Science 354, 213-217. doi: 10.1126/science.aaf8852

Goodbourn, S., Didcock, L., and Randall, R. E. (2000). Interferons: cell signalling, immune modulation, antiviral response and virus countermeasures. J. Gen. Virol. 81, 2341-2364. doi: 10.1099/0022-1317-81-10-2341

Guo, Z., Chen, L. M., Zeng, H., Gomez, J. A., Plowden, J., Fujita, T., et al. (2007). NS1 protein of influenza A virus inhibits the function of intracytoplasmic pathogen sensor, RIG-I. Am. J. Respir. Cell Mol. Biol. 36, 263-269. doi: 10.1165/rcmb.2006-0283RC

Hagenaars, T. J., Fischer, E. A., Jansen, C. A., Rebel, J. M., Spekreijse, D., Vervelde, L., et al. (2016). Modelling the innate immune response against avian influenza virus in chicken. PLoS One 11:e0157816. doi: 10.1371/journal.pone.0157816

Hayden, M. S., and Ghosh, S. (2011). NF-кB in immunobiology. Cell Res. 21, 223-244. doi: 10.1038/cr.2011.13

Helin, A. S., Wille, M., Atterby, C., Järhult, J. D., Waldenström, J., and Chapman, J. R. (2018). A rapid and transient innate immune response to avian influenza infection in mallards. Mol. Immunol. 95, 64-72. doi: 10.1016/j. molimm.2018.01.012

Holmes, E. C., Ghedin, E., Miller, N., Taylor, J., Bao, Y., St George, K., et al. (2005). Whole-genome analysis of human influenza A virus reveals multiple persistent lineages and reassortment among recent H3N2 viruses. PLoS Biol. 3:e300. doi: 10.1371/journal.pbio.0030300

Isaacs, A., and Lindenmann, J. (1987). Virus interference. I. The interferon. By A. Isaacs and J. Lindenmann, 1957. J. Interf. Res. 7, 429-438. doi: 10.1089/ jir.1987.7.429

Janeway, C. A. Jr. (1989). Approaching the asymptote? Evolution and revolution in immunology. Cold Spring Harb. Symp. Quant. Biol. 54, 1-13. doi: 10.1101/ SQB.1989.054.01.003 contributed to isolation and identification of virus. YWa, YLW, and $\mathrm{ZH}$ performed the phylogenetic analyses. YL, HC, and XZ commented on and revised the drafts of the manuscript. All authors contributed to the article and approved the submitted version.

\section{FUNDING}

This study was supported by the Heilongjiang Natural Science Foundation Program (LH2019C13) and the Surveillance of Wildlife Diseases from the National Forestry and Grassland Administration (2019076018) and the National Natural Science Foundation of China (81873312).

John, J. L. (1994). The avian spleen: a neglected organ. Q. Rev. Biol. 69, 327-351. doi: $10.1086 / 418649$

Kawai, T., and Akira, S. (2009). The roles of TLRs, RLRs and NLRs in pathogen recognition. Int. Immunol. 21, 317-337. doi: 10.1093/intimm/dxp017

Kida, H., Yanagawa, R., and Matsuoka, Y. (1980). Duck influenza lacking evidence of disease signs and immune response. Infect. Immun. 30, 547-553. doi: 10.1128/iai.30.2.547-553.1980

Kikkert, M. (2020). Innate immune evasion by human respiratory RNA viruses. J. Innate Immun. 12, 4-20. doi: 10.1159/000503030

Koerner, I., Kochs, G., Kalinke, U., Weiss, S., and Staeheli, P. (2007). Protective role of beta interferon in host defense against influenza A virus. J. Virol. 81, 2025-2030. doi: 10.1128/JVI.01718-06

Kuo, R. L., and Krug, R. M. (2009). Influenza a virus polymerase is an integral component of the CPSF30-NS1A protein complex in infected cells. J. Virol. 83, 1611-1616. doi: 10.1128/JVI.01491-08

Lee, D. H., Kwon, J. H., Noh, J. Y., Park, J. K., Yuk, S. S., Erdene-Ochir, T. O., et al. (2016). Pathogenicity of the Korean H5N8 highly pathogenic avian influenza virus in commercial domestic poultry species. Avian Pathol. 45, 208-211. doi: 10.1080/03079457.2016.1142502

Li, X., Lv, X., Li, Y., Peng, P., Zhou, R., Qin, S., et al. (2021). Highly pathogenic avian influenza $\mathrm{A}(\mathrm{H} 5 \mathrm{~N} 8)$ virus in swans, China, 2020. Emerg. Infect. Dis. 27, 1732-1734. doi: 10.3201/eid2706.204727

Li, X., Lv, X., Li, Y., Xie, L., Peng, P., An, Q., et al. (2022). Emergence, prevalence, and evolution of H5N8 avian influenza viruses in central China, 2020. Emerg. Microbes Infect. 11, 73-82. doi: 10.1080/22221751.2021.2011622

Livak, K. J., and Schmittgen, T. D. (2001). Analysis of relative gene expression data using real-time quantitative PCR and the 2(-Delta Delta C(T)) method. Methods 25, 402-408. doi: 10.1006/meth.2001.1262

Marshall, N., Priyamvada, L., Ende, Z., Steel, J., and Lowen, A. C. (2013). Influenza virus reassortment occurs with high frequency in the absence of segment mismatch. PLoS Pathog. 9:e1003421. doi: 10.1371/journal.ppat.1003421

Massin, P., Deleage, C., Oger, A., Briand, F. X., Quenault, H., and Blanchard, Y. (2013). Differential cellular gene expression in duck trachea infected with a highly or low pathogenic H5N1 avian influenza virus. Virol. J. 10:279. doi: $10.1186 / 1743-422 x-10-279$

Mibayashi, M., Martínez-Sobrido, L., Loo, Y. M., Cárdenas, W. B., Gale, M. Jr., and García-Sastre, A. (2007). Inhibition of retinoic acid-inducible gene I-mediated induction of beta interferon by the NS1 protein of influenza A virus. J. Virol. 81, 514-524. doi: 10.1128/JVI.01265-06

Muzyka, D., Rula, O., Tkachenko, S., Muzyka, N., Köthe, S., Pishchanskyi, O., et al. (2019). Highly pathogenic and low pathogenic avian influenza H5 subtype viruses in wild birds in Ukraine. Avian Dis. 63, 235-245. doi: 10.1637/11880-042718.1

Nguyen, D. C., Uyeki, T. M., Jadhao, S., Maines, T., Shaw, M., Matsuoka, Y., et al. (2005). Isolation and characterization of avian influenza viruses, including highly pathogenic $\mathrm{H} 5 \mathrm{~N} 1$, from poultry in live bird markets in Hanoi, Vietnam, in 2001. J. Virol. 79, 4201-4212. doi: 10.1128/JVI.79.7.4201-4212.2005

Nuñez, I. A., and Ross, T. M. (2019). A review of $\mathrm{H} 5 \mathrm{Nx}$ avian influenza viruses. Ther. Adv. Vaccines Immunother. 7, 2515135518821625. doi: $10.1177 / 2515135518821625$ 
Okamatsu, M., Tanaka, T., Yamamoto, N., Sakoda, Y., Sasaki, T., Tsuda, Y., et al. (2010). Antigenic, genetic, and pathogenic characterization of H5N1 highly pathogenic avian influenza viruses isolated from dead whooper swans (Cygnus cygnus) found in northern Japan in 2008. Virus Genes 41, 351-357. doi: $10.1007 /$ s11262-010-0530-3

Opitz, B., Rejaibi, A., Dauber, B., Eckhard, J., Vinzing, M., Schmeck, B., et al. (2007). IFNbeta induction by influenza A virus is mediated by RIG-I which is regulated by the viral NS1 protein. Cell. Microbiol. 9, 930-938. doi: 10.1111/j.1462-5822.2006.00841.x

Pantin-Jackwood, M. J., Costa-Hurtado, M., Shepherd, E., DeJesus, E., Smith, D., Spackman, E., et al. (2016). Pathogenicity and transmission of H5 and H7 highly pathogenic avian influenza viruses in mallards. J. Virol. 90, 9967-9982. doi: 10.1128/JVI.01165-16

Piaggio, A. J., Shriner, S. A., VanDalen, K. K., Franklin, A. B., Anderson, T. D., and Kolokotronis, S. O. (2012). Molecular surveillance of low pathogenic avian influenza viruses in wild birds across the United States: inferences from the hemagglutinin gene. PLoS One 7:e50834. doi: 10.1371/journal.pone.0050834

Pichlmair, A., Schulz, O., Tan, C. P., Näslund, T. I., Liljeström, P., Weber, F., et al. (2006). RIG-I-mediated antiviral responses to single-stranded RNA bearing 5'-phosphates. Science 314, 997-1001. doi: 10.1126/science.1132998

Rambaut, A., Pybus, O. G., Nelson, M. I., Viboud, C., Taubenberger, J. K., and Holmes, E. C. (2008). The genomic and epidemiological dynamics of human influenza A virus. Nature 453, 615-619. doi: 10.1038/nature 06945

Robertson, M. (1998). Innate immunity. Curr. Biol. 8, R595-R597. doi: 10.1016/ S0960-9822(98)70384-7

Servant, M. J., Grandvaux, N., and Hiscott, J. (2002). Multiple signaling pathways leading to the activation of interferon regulatory factor 3. Biochem. Pharmacol. 64, 985-992. doi: 10.1016/S0006-2952(02)01165-6

Sharma, S., tenOever, B. R., Grandvaux, N., Zhou, G. P., Lin, R., and Hiscott, J. (2003). Triggering the interferon antiviral response through an IKK-related pathway. Science 300, 1148-1151. doi: 10.1126/science.1081315

Simulundu, E., Ishii, A., Igarashi, M., Mweene, A. S., Suzuki, Y., Hang'ombe, B. M., et al. (2011). Characterization of influenza A viruses isolated from wild waterfowl in Zambia. J. Gen. Virol. 92, 1416-1427. doi: 10.1099/ vir.0.030403-0

Spackman, E., Swayne, D. E., Gilbert, M., Joly, D. O., Karesh, W. B., Suarez, D. L., et al. (2009). Characterization of low pathogenicity avian influenza viruses isolated from wild birds in Mongolia 2005 through 2007. Virol. J. 6:190. doi: $10.1186 / 1743-422 \mathrm{x}-6-190$

Sturm-Ramirez, K. M., Ellis, T., Bousfield, B., Bissett, L., Dyrting, K., Rehg, J. E., et al. (2004). Reemerging H5N1 influenza viruses in Hong Kong in 2002 are highly pathogenic to ducks. J. Virol. 78, 4892-4901. doi: 10.1128/ JVI.78.9.4892-4901.2004

Sturm-Ramirez, K. M., Hulse-Post, D. J., Govorkova, E. A., Humberd, J., Seiler, P., Puthavathana, P., et al. (2005). Are ducks contributing to the endemicity of highly pathogenic H5N1 influenza virus in Asia? J. Virol. 79, 11269-11279. doi: 10.1128/JVI.79.17.11269-11279.2005

Suttie, A., Deng, Y. M., Greenhill, A. R., Dussart, P., Horwood, P. F., and Karlsson, E. A. (2019). Inventory of molecular markers affecting biological characteristics of avian influenza A viruses. Virus Genes 55, 739-768. doi: $10.1007 / \mathrm{s} 11262-019-01700-\mathrm{z}$

Takeuchi, O., and Akira, S. (2010). Pattern recognition receptors and inflammation. Cell 140, 805-820. doi: 10.1016/j.cell.2010.01.022

Talon, J., Horvath, C. M., Polley, R., Basler, C. F., Muster, T., Palese, P., et al. (2000). Activation of interferon regulatory factor 3 is inhibited by the influenza A virus NS1 protein. J. Virol. 74, 7989-7996. doi: 10.1128/ JVI.74.17.7989-7996.2000

Tong, S., Zhu, X., Li, Y., Shi, M., Zhang, J., Bourgeois, M., et al. (2013). New world bats harbor diverse influenza A viruses. PLoS Pathog. 9:e1003657. doi: 10.1371/journal.ppat.1003657

Vanderven, H. A., Petkau, K., Ryan-Jean, K. E., Aldridge, J. R. Jr., Webster, R. G., and Magor, K. E. (2012). Avian influenza rapidly induces antiviral genes in duck lung and intestine. Mol. Immunol. 51, 316-324. doi: 10.1016/j. molimm.2012.03.034

Wang, X., Li, M., Zheng, H., Muster, T., Palese, P., Beg, A. A., et al. (2000). Influenza A virus NS1 protein prevents activation of NF-kappaB and induction of alpha/beta interferon. J. Virol. 74, 11566-11573. doi: 10.1128/ JVI.74.24.11566-11573.2000

Webster, R. G., Bean, W. J., Gorman, O. T., Chambers, T. M., and Kawaoka, Y. (1992). Evolution and ecology of influenza A viruses. Microbiol. Rev. 56, 152-179. doi: 10.1128/mr.56.1.152-179.1992

Webster, R. G., Yakhno, M., Hinshaw, V. S., Bean, W. J., and Murti, K. G. (1978). Intestinal influenza: replication and characterization of influenza viruses in ducks. Virology 84, 268-278. doi: 10.1016/0042-6822(78)90247-7

Wu, Y., Wu, Y., Tefsen, B., Shi, Y., and Gao, G. F. (2014). Bat-derived influenzalike viruses $\mathrm{H} 17 \mathrm{~N} 10$ and H18N11. Trends Microbiol. 22, 183-191. doi: 10.1016/j.tim.2014.01.010

Wu, S., Zhang, J., Huang, J., Li, W., Liu, Z., He, Z., et al. (2019). Immunerelated gene expression in ducks infected With waterfowl-origin H5N6 highly pathogenic avian influenza viruses. Front. Microbiol. 10:1782. doi: 10.3389/ fmicb.2019.01782

Zhang, Z., Chen, D., Ward, M. P., and Jiang, Q. (2012). Transmissibility of the highly pathogenic avian influenza virus, subtype $\mathrm{H} 5 \mathrm{~N} 1$ in domestic poultry: a spatio-temporal estimation at the global scale. Geospat. Health 7, 135-143. doi: 10.4081/gh.2012.112

Zhang, Y., Zhang, Q., Kong, H., Jiang, Y., Gao, Y., Deng, G., et al. (2013). H5N1 hybrid viruses bearing 2009/H1N1 virus genes transmit in Guinea pigs by respiratory droplet. Science 340, 1459-1463. doi: 10.1126/ science. 1229455

Zhu, X., Yu, W., McBride, R., Li, Y., Chen, L. M., Donis, R. O., et al. (2013). Hemagglutinin homologue from $\mathrm{H} 17 \mathrm{~N} 10$ bat influenza virus exhibits divergent receptor-binding and $\mathrm{pH}$-dependent fusion activities. Proc. Natl. Acad. Sci. U. S. A. 110, 1458-1463. doi: 10.1073/pnas.1218509110

Conflict of Interest: The authors declare that the research was conducted in the absence of any commercial or financial relationships that could be construed as a potential conflict of interest.

Publisher's Note: All claims expressed in this article are solely those of the authors and do not necessarily represent those of their affiliated organizations, or those of the publisher, the editors and the reviewers. Any product that may be evaluated in this article, or claim that may be made by its manufacturer, is not guaranteed or endorsed by the publisher.

Copyright (C) 2022 Zhai, Liu, Li, Lv, Wu, Li, Lin, Yin, Lan, Du, Wu, Wen, Wang, Wang, Hou, Li, Chai and Zeng. This is an open-access article distributed under the terms of the Creative Commons Attribution License (CC BY). The use, distribution or reproduction in other forums is permitted, provided the original author $(s)$ and the copyright owner(s) are credited and that the original publication in this journal is cited, in accordance with accepted academic practice. No use, distribution or reproduction is permitted which does not comply with these terms. 